\title{
Author Correction: Competition for priority harms the reliability of science, but reforms can help
}

Leonid Tiokhin (D), Minhua Yan (D) and Thomas J. H. Morgan (DD

Correction to: Nature Human Behaviour https://doi.org/10.1038/s41562-020-01040-1, published online 28 January 2021.

In the version of this article initially published, the disclosure of a financial competing interest was inadvertently omitted: author Leonid Tiokhin is co-founder of the company Red Team Market, which provides independent, paid criticism of scientific research. This error has been corrected in the PDF and HTML versions of this article.

Published online: 8 March 2021

https://doi.org/10.1038/s41562-021-01089-6

(C) The Author(s), under exclusive licence to Springer Nature Limited 2021 